\title{
Abolição e Carnaval: performance e experiência social negra em Trinidad (cc. 1790-1850)
}

Recebido: 30-08-2018

Aprovado: 11-11-2018

Eric Brasil ${ }^{1}$

\section{Introdução}

Localizada a aproximadamente vinte quilômetros do litoral da Venezuela, possuindo em torno de três mil quilômetros quadrados, a ilha de Trinidad não despertaria muita atenção de seus conquistadores espanhóis ao longo do século XVI. Eles estavam por demais interessados em extrair até a última grama de ouro e prata de suas colônias continentais. Assim, entre a chegada de Colombo, em 1498, e a fundação da primeira cidade na ilha - San Josephe de Oruna -, em 1592, passaram-se 94 anos (Wooding, 1960, p. 144).

Nos séculos XVII e XVIII, tentativas modestas de implementação de plantations de tabaco e cacau foram realizadas. Apesar de abrirem demanda ao tráfico de africanos escravizados, não obtiveram êxito no período de domínio espanhol (Matthews, 2007, pp. 8789). Na década de 1780, o Rei espanhol assinou a "Cédula de Población" permitindo que estrangeiros de nações amigas se estabelecessem em Trinidad, desde que professassem sua religião Católica Romana. A partir de então, se intensificou a imigração de proprietários franceses, que chegavam à ilha acompanhados de seus escravos (Wooding, 1960, p. 144). Essa migração foi impulsionada pela Revolução Francesa (1789) e pela Revolução do Haiti (1791), visto que muitos proprietários franceses que viviam em Santo Domingo buscaram asilo em Trinidad. Isso explica a existência de uma "aristocracia fundiária francesa" numa ilha que nunca pertenceu à França.

\footnotetext{
1 Professor de História da América e coordenador do curso de História da Universidade da Integração Internacional da Lusofonia Afro-brasileira, campus dos Malês, Bahia. Coordenador Nacional do GT Emancipações e Pós-Abolição da Anpuh. E-mail: profericbrasil@unilab.edu.br
} 


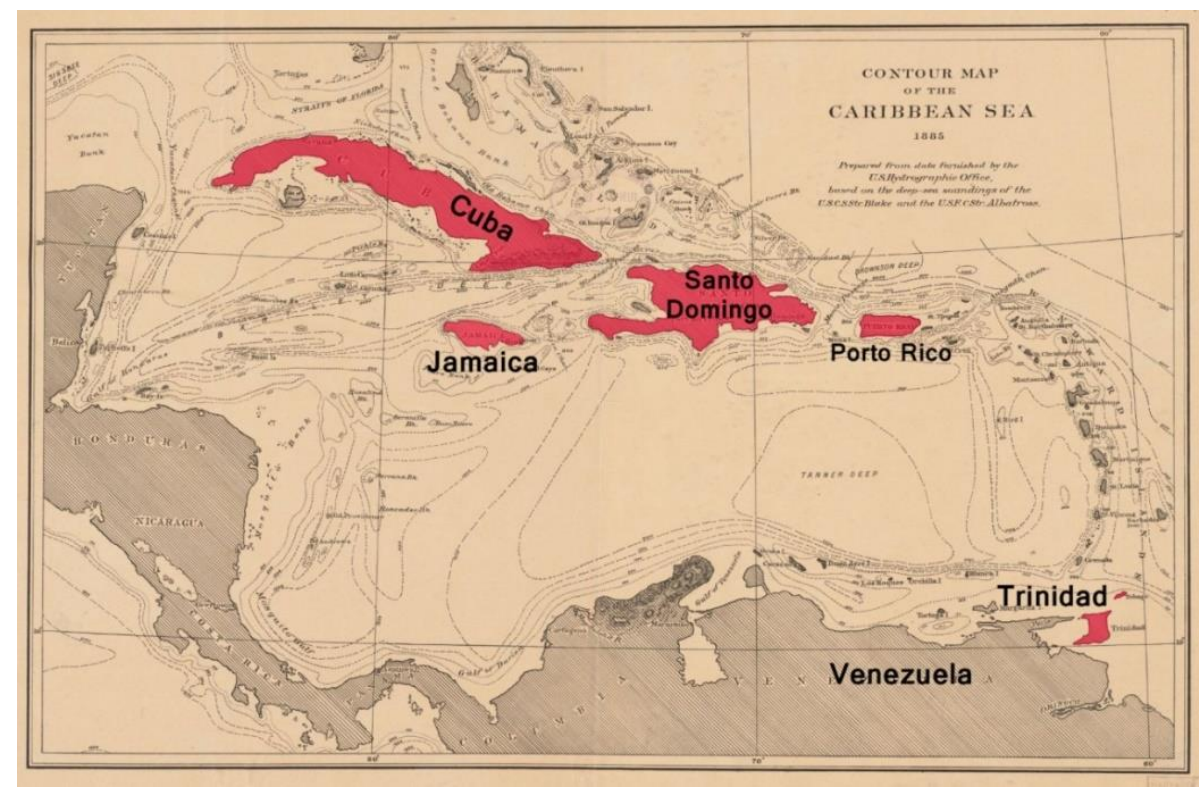

Figura 1. Mapa do Caribe a partir de: United States. Contour Map of the Caribbean Sea 1885. Cambridge, Mass: Museum of Comparative Zoology, 1894.

Também nos ajuda a compreender como a república de Trinidad e Tobago, que foi colônia inglesa por 165 anos, oficialmente protestante e anglófona, integrante do Commonwealth, é internacionalmente reconhecida por seu carnaval exuberante, elemento fundamental na identidade nacional do país. Os 300 anos de domínio espanhol, mesmo que insipiente em diversos aspectos, proporcionou à população local, tanto espanhóis e seus descendentes, quanto escravizados africanos e crioulos, mestiços e indígenas, algum espaço festivo para ocupar as ruas, através da tradição carnavalesca ibérica e católica (López, 2013). A festa carnavalesca não desapareceria com a conquista inglesa da ilha em 1797, pelo contrário, seus sentidos se transformariam diante dos novos desafios impostos pela colonização britânica. Antagônica às raízes ibéricas da ilha, buscaria reprimir seu carnaval como um caminho para impor a cultura britânica e efetivar a colonização ainda no início do século XIX.

Nas décadas de 1870 e 1880, especialmente após a revolta do Canboulay de $1881{ }^{2}$ encontramos artigos em jornais, produções de memorialistas e cronistas refletindo sobre a história do Carnaval na ilha de Trinidad. A maioria desses textos constrói uma imagem nostálgica do que seria o tempo do carnaval inocente, divertido e pacífico. Esse tempo de

\footnotetext{
${ }^{2}$ A revolta ocorrida no carnaval de 1881 constitui um marco na história da cidade de Port-of-Spain e de toda a colônia. Em resposta a medidas repressivas adotadas pelo chefe de polícia, Capitão Baker, entre os anos de 1877 e 1881, os variados e historicamente rivais grupos de Canboulay da cidade se unem contra a polícia. Utilizando cacetes e reivindicando direitos, os revoltosos conquistam a garantia de manter sua prática carnavalesca, recebendo a anuência do governador. Para uma análise aprofundada da revolta e os consequentes debates sobre direitos e cidadania em Trinidad ver (Brasil, 2016a; Brasil, 2016b)
} 
prazer estaria localizado no período anterior ao ano de 1838, ano da abolição definitiva da escravidão no Caribe de colonização britânica. Descrevendo o período como um tempo mitológico de harmonia, prazer e lazer, os textos das décadas de 1870 e 1880 relatam o carnaval como uma festa exclusiva das famílias dos fazendeiros de origem francesa. Com a abolição da escravidão tudo mudaria e o carnaval seria transformado numa sucessão de orgias e desordens (Day, 1852; Fraser, 1896; Borde, 1876).

Essa narrativa sobre a história do carnaval - reforçando a "desordem" e a "barbárie" trazida pelos libertos para a festa - acabou sendo também utilizada por parte da historiografia para explicar a entrada da população negra no festival. Tornando-se uma espécie de mito fundador do carnaval negro de Trinidad, como se antes de 1838 escravizados e negros libertos e livres não tivessem outras formas de mobilização, não participassem de festas, e mesmo do carnaval (Liverpool, 2001).

A importância e as mudanças trazidas pela abolição da escravidão foram cruciais para a transformação do carnaval, como veremos adiante. Contudo, ela precisa ser entendida como um processo a partir de mobilizações negras que já existiam anteriormente e com as relações sociais na ilha entre 1780 e 1850 - não apenas como um reflexo automático da assinatura do ato que aboliu a escravidão.

Por conseguinte, o objetivo central desse artigo é analisar os sentidos das mobilizações e performances negras em Trinidad entre o início da ocupação britânica da ilha, na última década do século XVIII, e as primeiras décadas do período pós-abolição, através de uma perspectiva de história social da cultura, enfocando as experiências dos sujeitos sociais em seu contexto. Para tanto, o texto está dividido em três tópicos: no primeiro, iremos analisar as formas de participação de homens e mulheres negras durante a vigência do regime escravista na ilha, assim como as tentativas coloniais de repressão e controle e os argumentos da imprensa local na construção do mito do carnaval branco, ordeiro e civilizado (sic); em seguida, buscamos investigar os impactos demográficos, nas relações de trabalho e nas tensões sociais após 1838 para a população negra da colônia; por fim, focamos a análise na formação do Canboulay negro entre as décadas de 1830 e 1850, propondo uma reflexão sobre seus sentidos políticos num contexto de liberdade.

\section{Carnaval durante a escravidão}

Se compararmos a colonização inglesa das ilhas vizinhas, como Jamaica e Barbados, perceberemos que Trinidad possuía uma população escrava menor e muito mais recente. A entrada maciça de escravizados na ilha se deu a partir da década de 1780 - com a entrada de 
proprietários franceses - e, sobremaneira, a partir de 1797, com a ocupação inglesa e a intensificação da produção de cana-de-açúcar. O tráfico de escravos foi proibido em 1805, dois anos antes de sua extinção completa pelos ingleses. Dentre os escravizados, além dos chegados diretamente da África, muitos vinham das ilhas vizinhas, como Barbados e Granada - colônias britânicas - e Guadalupe e Martinica - colônias francesas.

O período entre o Natal e o Ano Novo, entre 1797 e 1830, era a época permitida pelo governo colonial para o divertimento dos escravizados. Segundo Cowley, esse período foi marcado pela formação e desfiles dos Regiments:

A filiação dessas sociedades dançantes negras estavam espalhadas entre grupos [...] cuja origem crioula provinha de vários lugares do Caribe - por exemplo, Martinica, Guadalupe, ou Granada. Participantes também incluíam escravos que haviam chegado a Trinidad diretamente da África e negros livres. Muitos membros recebiam títulos (e presumivelmente, funções) e havia cerimonial estruturado e formalidades disciplinadas (Cowley, 1992, p. 179). ${ }^{3}$

Esses grupos de indivíduos negros desfilavam nas ruas no período natalino, constituídos numa estrutura militarizada, com cargos eleitos de rei, rainha, com cantos e tambores de origem africana, especialmente na capital da colônia, a cidade de Port-of-Spain. Tais grupos estão amplamente presentes em regiões impactadas pela diáspora africana: as Congadas, Cucumbis e Folias de Rei no sudeste brasileiro, os Cabildos cubanos, os grupos de índios em Nova Orleans, estiveram presentes ao longo do século XIX nas ruas de grandes cidades atlânticas desfilando seus préstitos com estrutura militar, reis, rainhas, tambores inicialmente no período das festas natalinas e depois muitos ocuparam os carnavais (Brasil, 2014; Meitchell, 2002; Moore, 1997; Nepomuceno, 2016).

Nesse contexto, entre finais do século XVIII e início do XIX, o período de Carnaval estaria bastante ligado aos grupos de proprietários de terras francófonos, sendo uma época marcada por bailes de máscaras, espetáculos teatrais e performances satíricas que se estendia desde o Ano Novo até a Quarta-feira de Cinzas. Segundo Pierre Gustave-Louis Borde (18201891), historiador de Trinidad de ascendência francesa que escreveu em 1876 Histoire de l'île de la Trinidad sous le gouvernement espagnol,

Os prazeres das refeições na mesa de jantar e piqueniques somavam-se àqueles de música e dança. Seguiam-se nada mais que concertos e bailes. Haviam almoços e jantares, festas de caça e expedições no rio, assim como o carnaval, que durava desde o Natal até a quarta-feira de cinzas. Não era nada além de um longo período de

\footnotetext{
${ }^{3}$ Todas as traduções de fontes e bibliografias do inglês para o português são livres e feitas pelo autor. 
banquetes e prazeres. Naturalmente, todos esses divertimentos aconteciam numa atmosfera de alegria geral, e cada um fazia esforço especial para demonstrar espírito de amabilidade. (Borde, apud. Cowley, 1992, p. 174)

Para Borde, o carnaval era tempo de vivenciar uma experiência festiva eurocêntrica, com seus bailes, banquetes, caças, expedições em rios, tudo numa atmosfera de alegria e amabilidade.

O historiador L. M. Fraser, autor de History of Trinidad, volumes um e dois, publicados em 1891 e 1896 respectivamente, Inspetor Comandante de Polícia entre 1874 e 1877, reforça a ideia de que o carnaval havia sido uma festa controlada e exclusiva das “classes altas” após a abolição da escravidão:

Em tempos passados e antes do período da emancipação dos escravos, o carnaval era mantido com muito espírito pelas classes superiores. Existem muitas pessoas ainda vivas que lembram do baile de máscaras dado no St. Ann pelo Governador, Sir Ralph Woodford, e também [lembram] que os membros dirigentes da sociedade costumavam, nos dias de carnaval, dirigir através das ruas de Port-of-Spain mascarados, e à noite, iam de casa em casa que eram deixadas abertas para a ocasião (The National Archives - Colonial Office 295/289).

Entretanto, essas descrições das décadas de 1870 e 1880 mostram um tom romantizado e nostálgico que fala muito sobre a época em que foram escritas. Período de intensificação das tensões sociais, especialmente entre grupos carnavalescos negros e as autoridades republicanas, que culminaria com a Revolta do Canboulay de 1881 (Brasil, 2016b). E buscava construir uma memória da festa que excluísse ou silenciasse a presença negra antes da Abolição. Porém, as ruas nos dias de Momo não eram socialmente homogêneas e socialmente pacíficas como Borde e Fraser tentaram nos fazer crer. A participação negra em festas e performances públicas esteve sob rígido controle e vigilância do governo colonial desde o final do século XVIII. Como demonstra Cowley,

A lei espanhola permaneceu válida em Trinidad até a década de 1830, mas as regulamentações policiais, publicadas dois ou três meses depois da conquista britânica da ilha, controlavam estritamente atividades de dança nas comunidades negras livres e escravas. Essencialmente, para pessoas de cor realizarem danças, entretenimentos ou encontros religiosos depois das oito da noite, era preciso autorização; escravos eram autorizados a danças, quando licenciados, apenas até as oito da noite. Mais regulamentações seguiram em 1801, com a 'proibição de danças de negros em cidades', e em 1807 aparece que 'pessoas de cor' eram permitidas 'realizar bailes e assembleias sujeitas a doação aos pobres de 16 dólares' (Cowley 1992, p. 180).

Tanto negros livres quanto escravizados precisavam recorrer à licenças do governo colonial para realizar festas, reuniões e bailes. ${ }^{4}$ Outrossim, tais proibições indicam que havia

\footnotetext{
${ }^{4}$ Nos documentos coloniais preservados nos arquivos ingleses não pude encontrar tais licenças. 
“danças de negros nas cidades" já na década de 1800. E, mesmo fontes dos jornais apontam para a participação negra no Carnaval antes de 1834. Em artigo de 22 de janeiro de 1833, o Port-of-Spain Gazette relatava o caso da prisão de duas pessoas mascaradas.

$\mathrm{Na}$ tarde de domingo, uma tentativa foi feita pelo Sr. Peake (Assistente do delegado) para averiguar a vergonhosa violação do Sabbath pelas ordens baixas da população, que estavam acostumados, naquela época do ano a se mascarar e criar distúrbios no domingo. Ele prendeu duas pessoas que estavam mascaradas e os trancou uma sela. No retorno da realização desse dever necessário, sua casa havia sido atacada por um grande aglomerado da ralé que quebrou todas as janelas e atacaram Sr. Peake [sendo ele] agredido e de várias formas mal tratado (PORT-OF-SPAIN GAZETTE. 22/01/1833).

Pessoas de "classes baixas" estavam acostumadas nessa época do ano, janeiro, a se mascarar. A casa e o próprio policial que efetuou a prisão dos mascarados foram atacados em represália a prisão dos indivíduos mascarados. Numa demonstração de insatisfação coletiva, fruto do que foi considerada uma atitude injusta, as "classes baixas" decidiram reagir com insubordinação e violência. O jornal complementa buscando estabelecer limites para o período carnavalescos e se empenha em associar o carnaval feito pelas "classes baixas" à violência:

Em referência ao assunto acima, é importante ressaltar, que a prática de iniciar o carnaval várias semanas antes da quarta-feira de cinzas, é contrário ao costume espanhol, assim como à lei. Na Espanha, e em todas as possessões espanholas, o carnaval é realizado em três dias; a prática de estender as diversões do Bacanal pelo espaço de um mês ou dois, é italiano, e foi introduzido por estrangeiros. Isso se tornou um grande inconveniente na ilha, já que os eventos mais criminosos e indecentes ocorrem durante o carnaval, ao qual os magistrados locais fazem bem em se esforçar para suprimir (PORT-OF-SPAIN GAZETTE. 22/01/1833).

Portanto, mesmo antes da abolição da escravidão é possível encontrar registros da mobilização negra em busca de espaços de autonomia para realizar suas próprias festas e ocupar as ruas com suas tradições. Tais tradições remetem ao caráter ibérico e católico da ocupação espanhola da ilha. Como demonstra Rafael Bréa López, as festas carnavalescas representavam desde o período colonial, nos territórios sob domínio espanhol, um momento de participação das mais variadas camadas sociais, com múltiplas performances (López, 2013).

Se até 1834 essa maior mobilização se dava no período entre Natal e Ano Novo, depois percebemos um movimento dessas práticas em direção aos dias de Carnaval. Na interpretação de Cowley, o contexto social e político de Trinidad tiveram um peso significativo na maior presença negra nos carnavais a partir da década de 1830 "Em Trinidad, onde os efeitos da 
escravidão foram amenizados pelo melhoramento de condições locais, escravos eram provavelmente menos inibidos do que em outras ilhas do Caribe britânico. Com a confirmação de sua liberdade no horizonte, então, e uma plantocracia branca deprimida pela perda iminente de seus escravos, a participação negra no carnaval atingiu a maturidade em fevereiro de 1834" (Cowley, 2003)

\section{Trinidad e o Fim da Escravidão no Caribe sob domínio britânico}

Nesse contexto, os debates acerca da proibição do tráfico de africanos escravizados passa a ocupar a primeira ordem nos debates britânicos. A revolta escrava da década de 1760 na Jamaica e especialmente a Revolução do Haiti, colocaram em questão o temor da insurreição generalizada de africanos escravizados. Tanto abolicionistas quando fazendeiros passam a entender que a solução para evitar revoltas sem encarecer ou diminuir a produção seria o aumento do número de crioulos, e isso só seria possível com melhorias nas condições de vida dos escravizados e o fim do tráfico (Fergus, 2009, p. 761).

O temor de uma possível "Emancipação Revolucionária", como chama o historiador Claudius Fergus, coloca em discussão a questão “do real valor da escravidão racial” e em seu centro estava o debate entre prosperidade e segurança (Fergus, 2013). O pragmatismo da luta pela abolição do tráfico inglês, liderada por Wilberforce e outros, foi sobremaneira direcionada pela preocupação em manter a ordem e a segurança interna, temor esse ditado pela insatisfação e ações dos escravizados nas ilhas do Caribe, e não apenas fruto do humanitarismo inglês ou do determinismo econômico da expansão capitalista britânica (Fergus, 2009, p. 764).

Trinidad surge como elemento chave nas discussões sobre a questão do tráfico transatlântico de escravos e do próprio futuro do Império colonial. A ilha recém-conquistada, em 1797, apresentava terras férteis e disponíveis, se configurando como um atrativo mercado de escravos. Como demonstrou Gelien Matthews, em estudo sobre as relações da colônia de Trinidad com os debates sobre a abolição do tráfico de escravos pelos britânicos, a exportação de açúcar praticamente dobrou entre 1799 e 1802, aumentando a demanda por africanos escravizados (Matthews, 2007).

Entre 1802 e 1804 desembarcam na ilha mais de dez mil africanos escravizados. Essa conjuntura possibilitou aos abolicionistas argumentarem que Trinidad poderia ser um novo Santo Domingo, e que o fim do tráfico seria fundamental para a manutenção da segurança em 
todo o Caribe. Não podemos esquecer que entre 1793 e 1815 o império britânico empreendeu guerra contra o Haiti revolucionário e sofreu com inúmeras derrotas, gerando milhares de mortos e um prejuízo de milhões de libras (Fergus, 2009).

Nesse período, importantes abolicionistas e membros do Parlamento, liderados por George Canning, iniciam uma campanha para que Trinidad fosse um novo modelo de colônia. ${ }^{5}$ A experiência deveria ser baseada em uma "colonização crioula", recebendo soldados oriundos dos regimentos de negros das Índias Ocidentais, africanos livres e descendentes de ilhas vizinhas, trabalhadores da Venezuela, ameríndios das missões religiosas, imigrantes asiáticos. Dessa forma, ainda em 1805, o tráfico é proibido para Trinidad, dois anos antes da abolição definitiva e a colônia passa a receber os primeiros assentamentos de negros livres e imigrantes (Fergus, 2009 e 2013).

Nos anos 1820, segundo Drescher, o tema da abolição definitiva da escravidão ganharia força entre os abolicionistas britânicos. Entretanto, não devemos compreender a abolição da escravidão nas colônias inglesas como fruto das campanhas humanitárias do abolicionismo metropolitano, como preconizam os trabalhos de Seymor Drescher. ${ }^{6}$ Como demonstram as obras de Emília Viotti da Costa, Michael Craton, Mary Turner, Claudius Fergus, Beckles e Matthews, os escravizados das colônias inglesas do Caribe nunca deixaram de exercer seu papel de protagonistas na luta pela abolição definitiva da escravidão. Apesar do temor e violência dos fazendeiros e da desconfiança dos próprios abolicionistas metropolitanos, eles seriam sujeitos de sua própria história, influenciando diretamente no curso da abolição com ações bem organizadas e muitas vezes sacrificantes, especialmente entre as décadas de 1810 e 1830, quando politizaram revoltas ao ponto de acelerar sua liberdade, com muito sangue e lágrimas (Beckles, 1989; Beckles e Shepherd, 2007; Fergus, 2013; G Matthews, 2006).

A conduta revoltosa dos escravizados em todo Caribe informou o governo britânico e as políticas abolicionistas do outro lado do Atlântico: o fim do tráfico, as políticas de melhoramento nas condições de trabalho [amelioration] e na vida cotidiana; a busca pela crioulização das sociedades coloniais - ou seja, diminuição do número de africanos e aumento

\footnotetext{
${ }^{5}$ George Canning (1770-1827) ocupou cargos econômicos no governo de Pitt, e nos anos 1820 seria responsável pelas políticas de "melhoramento".

${ }^{6}$ Movimentos metropolitanos seguiram estratégias já familiares àqueles que lutaram pelo fim do tráfico de africanos escravizados entre o final do século XVIII e início do XIX: organização local, panfletos e campanhas de petições nacionais, aliadas a moções [motions] abolicionistas no Parlamento. Contudo, novos fatores foram importantes desse movimento metropolitano: participação decisiva das mulheres - através da formação de sociedades femininas em prol da abolição -, ações que ultrapassavam as grandes cidades, e a maior participação de denominações religiosas, como os Metodistas e Batistas e especialmente os Quackers. (Drescher 2009, p. 252-54).
} 
de escravizados nascidos nas Índias Ocidentais -, o aumento da cristianização do trabalho escravo; e a própria abolição definitiva (Fergus, 2013).

O Emancipation act, assinado em 1833, instituíam quatro pontos que marcariam a passagem da escravidão para o trabalho livre e assalariado no Caribe.

Todos os escravos seriam libertados simultaneamente sem nenhuma provisão de restrições sociais especiais. Um novo status, o de aprendizes, obrigaria os ex-escravos a trabalharem para seus ex-senhores de quatro a seis anos, durante uma parte fixa de cada dia de trabalho. Os senhores receberiam uma indenização financeira calculada em cerca de $40 \%$ do valor de mercado de seus escravos. O fundo de indenização foi estabelecido em 20 milhões de libras - uma enorme quantia de dinheiro para um governo cuja plataforma de campanha fora a austeridade (Drescher, 2011, p. 373).

Segundo o historiador nigeriano David Olusoga, o montante da indenização paga aos 46 mil proprietários de escravos britânicos corresponderia a 16 bilhões de libras atualmente. ${ }^{7}$ Portanto, como nos alertou Eric Foner, o processo prezou pelo "respeito pela ordem, processos legais e direitos de propriedade". Os fazendeiros permaneceram com o controle sobre as terras e, em muitos casos, com o poder político nas colônias e ainda foram indenizados, porém, "ninguém propôs indenizar os escravos por seus anos de trabalho não remunerado" (Foner 1988, p. 33). Como concluiu Drescher, "a liberdade civil viria à custa do trabalho livre limitado para os ex-escravos, do aumento dos preços para os consumidores e da elevação dos impostos para os metropolitanos" (Drescher 2011, p. 373).

Mantendo essa linha de reformas e almejando sempre a manutenção da ordem e o compromisso com a legalidade, o governo britânico estabeleceu o sistema do "aprendizado" [Apprenticeship], que passaria a valer a partir do dia em que o Slavery Abolition Act entrou em vigor no dia 01 de agosto de 1834. Seu objetivo seria "suavizar a transição da escravatura para o trabalho livre" e "fomentar boas relações entre fazendeiro e liberto e remoldar a cultura dos ex-escravos", familiarizando-os com o mercado de trabalho assalariado (Foner 1988, p. 36-37). Todos os ex-escravos deveriam trabalhar no máximo 45 horas por semana nas fazendas de seus ex-senhores, por um período que variaria entre quatro e seis anos (Yelvington et al. 2011, p. 298).

Quanto mais o tempo avançava, maior era a insatisfação e ação dos libertos contra o sistema do aprendizado - este sempre amparado legalmente por magistrados empenhados em punir os trabalhadores insatisfeitos. A contínua pressão dos libertos nas colônias se aliou ao lobby antiescravista na metrópole, levando à extinção do Aprendizado em 1838, dois anos

\footnotetext{
7 http://www.theguardian.com/world/2015/jul/12/british-history-slavery-buried-scale-revealed acessado em $29 / 08 / 2018$.
} 
antes do previsto. Em Trinidad, o número de "aprendizes" girava em torno de $80 \%$ da população geral.

Em Trinidad foi instalado o modelo de Colônia da Coroa [Crown Colony]. Seus principais cargos administrativos estavam diretamente subjugados ao controle e autoridade do Colonial Office, na figura do Secretary of State for the Colonies. Mesmo as decisões do governador deveriam ser comunicadas e justificadas. O governador contava também com um Conselho Executivo - "um corpo puramente consultivo, compreendendo o Secretário Colonial, o Procurador Geral e o Tesoureiro Colonial, tendo o Governador como presidente" (Wooding 1960, p. 150). Ou seja, nesse sistema, não havia uma assembleia legislativa eleita por voto local, como nas demais colônias, Jamaica, por exemplo. Tal característica impunha sérios limites à representatividade das elites locais perante o governo metropolitano.

Ao chegar a 1838, Trinidad, a nova Colônia da Coroa, representava o modelo para o futuro das coloniais do império britânico: baseada na importação de trabalhadores "livres", na transição "pacífica" da escravidão para a liberdade e no respeito à legalidade e na lealdade à coroa - mantendo nas mãos do governo metropolitano o controle rígido dos poderes executivos e legislativos.

Após a abolição definitiva da escravidão, os novos súditos da rainha (mais de 20 mil ex-escravos), submetidos a um governo colonial que não pretendia conceder brechas para que se fizessem representar, queriam mais. Empenharam-se em lutar e conquistar espaços que antes lhes eram vedados, como o próprio Carnaval, como veremos a seguir.

\section{Pós-Abolição e carnaval: tensões sociais, imigração e repressão}

As comemorações pelo Emancipation day, a partir de 1838, com o fim do Aprendizado, ocorriam no dia 01 de agosto. Contudo, em algum momento dos anos 1840 essa celebração foi incorporada aos dias de carnaval. Segundo Earl Lovelace, a administração colonial, ao invés de retirar a ideia de abolição do calendário, forneceu

\footnotetext{
à Emancipação a oportunidade de penetrar o carnaval oficial e transformá-lo num palco para a afirmação da liberdade e expressão do triunfo do espírito humano num teatro de rua [com] música, dança, discurso, som e movimento. Podemos argumentar também que, o governo colonial dos anos 1840 escolheu o carnaval como a celebração [para] incorporar a [festa da] Emancipação não simplesmente por malícia, mas pelo conhecimento de que o Jouvay, carnaval das ruas, era ele mesmo criado e mantido pelas classes mais baixas de africanos" (Lovelace 1998, p. 54).
} 
Assim, a partir de 1838, quanto maior a participação negra no carnaval, maiores eram os ataques da imprensa contra a "degradação" da festa promovida pelos membros das "baixas classes". As tensões nas ruas aumentavam e as elites brancas se afastaram cada vez mais dos dias de Momo. As ações dos foliões negros, mesclando tradições africanas com a celebração da abolição, tornaram-se o alvo da repressão e crítica de fazendeiros e jornalistas, que comumente ignoravam as estruturas do evento e silenciavam suas práticas. Muitos começam a sugerir - e mesmo exigir - a extinção da festa, como na reportagem do Port-of-Spain Gazette, em 1840: "o costume de manter o carnaval, permitindo que camadas baixas da sociedade circulem pelas ruas em fantasias miseráveis, pertence a outros tempos e deve ser abolido" (apud Cowley 2003, p. 31). Como afirmou Andrew Pearse, houve uma completa mudança de tom em relação ao carnaval, passando de uma "untuosa autocongratulação" das elites brancas do período anterior à Abolição para uma "expectativa apreensiva de desgosto temperada pela condescendência em caso de desapontamento" (Pearse 1956, p. 183-84). Essa postura da imprensa se manteria ao longo de todo século XIX.

Nos anos 1840, as autoridades buscam aumentar o controle sobre o carnaval e limitam a festa a dois dias, proíbem o uso de máscaras nas ruas fora desse período. A intensificação da repressão sobre as práticas carnavalescas negras está estreitamente vinculada a um projeto mais profundo da colonização inglesa: enfraquecer o domínio político, econômico e cultural de grupos católicos, descendentes de franceses e espanhóis que compunham uma parcela importante da elite colonial de Trinidad desde o final do século XVIII.

Essas preocupações dialogam com as transformações sociais pelas quais a sociedade passava naquele momento. Os anos seguintes à abolição trouxeram consigo inúmeras mudanças nas relações de trabalho e na demografia da colônia, com impacto especial para a cidade de Port-of-Spain.

Como demonstrou Eric Foner, após 1838, por todo Caribe Inglês onde havia terra disponível - especialmente na Jamaica, em Trinidad e na Guiana Inglesa - o fracasso dos fazendeiros foi completo em sua tentativa de "intimidar os libertos para que permanecessem como uma força de trabalho dócil". Nessas áreas houve "uma deserção quase total das propriedades" (Foner, 1998. p. 41). Na Jamaica a emergência do campesinato negro foi mais impactante, gerando a queda dramática na produção de açúcar e o aumento significativo na produção de alimentos produzidos pelos camponeses negros (Foner 1988; Holt 1992, p. 115176). 
Caso parecido com o de Trinidad que, com sua entrada tardia na indústria açucareira caribenha, apresentava uma quantidade ainda grande de terra disponível para plantação e após 1838 surgem muitas aldeias camponesas (Foner 1988, p. 42). Nos anos 1830 e 1840, a produção de açúcar diminuiu e aumentaram as tensões entre fazendeiros e libertos (San Miguel 2011, p. 128-29). Nas palavras de Foner:

O conflito entre o desejo dos libertos de autonomia e a demanda dos fazendeiros por uma força de trabalho disciplinada uniu a história das sociedades caribenhas no pósemancipação. Em toda parte, os fazendeiros encaravam as aldeias camponesas como um desafio ao seu controle da mão-de-obra e como a causa de uma pressão inexorável que aumentava o salário dos remanescentes. Mas apenas em poucos casos eles foram inteiramente capazes de evitar seu surgimento (Foner 1988, p. 43).

Buscando viver e trabalhar "sob circunstâncias de sua própria escolha" (Foner 1988, p. 44), os libertos não se restringiram à produção de subsistência, e em alguns contextos forneceram produtos para o mercado interno e de exportação. No caso de Trinidad, a produção de cana-de-açúcar dos camponeses negros foi elevada, assim como um grande número de terras era cultivada com cacau (Foner 1988, p. 43; San Miguel 2011, p. 129-30). De acordo com Foner,

a maior parte das propriedades não foi adquirida por posse, mas por compra, com fundos laboriosamente acumulados do trabalho assalariado ou da venda de mercadorias, frequentemente através de associações cooperativas informais, sociedades de amigos e grupos religiosos. [Mas que obviamente esses camponeses estiveram] à mercê de condições climáticas, do mercado mundial e de autoridades políticas hostis, impedindo a possibilidade de um avanço econômico substancial (Foner 1988, p. 43-44).

Nesse contexto de redefinição e batalhas em torno dos sentidos da liberdade e das relações de trabalho e poder, os fazendeiros, visando aumentar o controle e pressionar o mercado de trabalho, iniciaram uma intensa política de importação de trabalhadores contratados vindos de variadas regiões do mundo. A imigração tornou-se elemento constituinte da vida da colônia de Trinidad. Entre 1844 e 1881 a população de imigrantes ficou sempre entre $41 \%$ e $46 \%$ do total da população (Liverpool 2001, p. 254).

Com apoio das autoridades coloniais, foi possível importar para o Caribe de colonização britânica mais de meio milhão de trabalhadores indianos, chamados de Coolies, entre 1838 e 1917. A Guiana Britânica recebeu em torno de 240 mil trabalhadores, enquanto Trinidad aportou 144 mil deles (Samaroo 2011, p. 248). Essa política de imigração visava manter os salários de toda a sociedade caribenha baixo. Tal situação, como afirma Foner, não seria possível sem a consolidação no Imperialismo britânico no século XIX e a ampla 
aceitação de ideias racistas sobre as populações tropicais 'e sua relutância em trabalhar' (Foner 1988, p. 47). Chineses e portugueses (das ilhas da Madeira, Cabo Verde e Açores) também desembarcaram em Trinidad, porém em menor escala (Samaroo 2011, 224; p. 234 40).

Os trabalhadores indianos em Trinidad assim que chegavam eram encaminhados para plantations sob contrato mínimo de cinco anos. Diferentemente da população afro-americana oriunda da experiência da diáspora e da escravidão, os indianos conseguiram manter um grau elevado de coesão e evitaram ao máximo o contato com outros grupos - o que fortalecia a política colonial britânica que se empenhava em manter tais grupos distantes. Através da manutenção de algumas instituições e de práticas endogâmicas puderam permanecer com sua identidade cultural e tradições mais fortalecidas, sem vivenciar um processo de crioulização acentuado, tão característico nas experiências afro-americanas. Para as autoridades coloniais e para os fazendeiros essa seria uma vantagem, visto que diminuía a possibilidade de alianças com os negros. A tensão entre indianos e negros acabou, portanto, sendo uma marca da sociedade de Trinidad no século XIX. Tanto por essa segregação cultural quanto pelo fato de a imigração de indianos garantir a pressão sobre os salários na ilha (Samaroo 2011, p. 248-53; Clarke 2011, p. 271). Entretanto, as tensões e rivalidades entre esses grupos estiveram menos presentes na cidade de Port-of-Spain até o início do século XX. Isso se explica pelo fato de os imigrantes indianos terem vivido e desenvolvido suas comunidades nas áreas de plantation, e sua presença nas áreas mais urbanizadas ter aumentado apenas no período posterior a virada do século.

Essa característica ajuda a compreender o caráter majoritariamente negro das populações de trabalhadores urbanos em Port-of-Spain, capital da colônia, ao longo de todo o século XIX. Essa presença maciça de sujeitos negros, entretanto, não deve nos levar a compreender essas experiências urbanas de forma homogênea. Milhares de caribenhos negros viram a ilha de Trinidad como possibilidade de uma vida melhor e migraram ao longo do século XIX. Segundo Liverpool, no ano de 1848, Trinidad recebeu 22.015 imigrantes, sendo 11.339 das ilhas das Índias Ocidentais britânicas, 3.990 africanos e 4.359 Indianos (Liverpool, 2001, p. 254). A grande maioria dos imigrantes caribenhos, diferentemente dos trabalhadores indianos, que logo eram levados para as plantations, se estabeleceu nas cidades de San Fernando e na capital Port-of-Spain. Conseguiram, em muitos casos, dominar atividades urbanas, como o caso dos Barbadianos negros que se destacaram como membros da força policial (Clarke 2011, p. 272; Liverpool 2001, p. 255). 
As intensas transformações sociais experimentadas no Pós-Abolição de Trinidad também impactaram nas formas de mobilização negra, nos embates, diálogos, negociações e enfrentamentos entre a população negra, as autoridades coloniais, os imigrantes das variadas regiões do mundo e as elites locais anglófonas - mais ligadas as forças metropolitanas - e francófonas - descendentes dos proprietários de terra e escravos do período anterior à conquista inglesa. ${ }^{8}$

Aqui é importante uma pequena digressão sobre os termos utilizados em Trinidad para caracterizar os grupos sociais. Segundo Bridget Brereton, em estudo minucioso sobre as relações raciais em Trinidad entre 1870 e 1900, os trinidenses coevos conviviam em uma "sociedade Crioula incluindo pessoas de descendência africana e europeia, e todos aqueles de origem mestiça [mixed descent], porém excluindo imigrantes asiáticos e do oriente médio." Assim, para esta autora,

A sociedade Crioula nas Índias Ocidentais, portanto, envolvia duas tradições culturais, a africana e a Europeia. Pressupunha um situação colonial, uma sociedade multirracial, e pluralismo cultural em maiores ou menores graus. Como o segmento europeu era o dominante, as formas da vida institucional se basearam em modelos europeus, embora muitos deles divergiram daqueles modelos, e as tradições africanas receberam baixo prestígio em comparação com aqueles derivados da Europa (Brereton 2002, p. 2)

Mesmo com a grande imigração de indianos, formando um quarto da população em 1870, esse grupo permaneceu à margem da sociedade Crioula até o século XX.

Essa sociedade Crioula é composta de "pessoas de cor" [coloured] - "indivíduo de ascendência mestiça de europeu e africano, provavelmente de compleição clara" -; negro [black] - "pessoa de ascendência africana sem misturas ou predominantemente africana, de compleição negra" -; africano - usado apenas para pessoas nascidas na África. Nesse contexto de finais do século XIX, Crioulo [Creole] significava pessoa nascida em Trinidad de ascendência europeia e africana, sendo esse o sentido quando usada sem adjetivos. Mas também encontramos White creole, French Creole. Esse último termo merece uma explicação mais detalhada. Nas palavras de Brereton, o termo creole em Trinidad possuía diversos significados e precisam ser entendidos.

\footnotetext{
${ }^{8}$ Com o avançar do século XIX, a língua inglesa passa a se tornar hegemônica. Por ser a língua oficial e pela implementação de um sistema pública de educação básica, a partir de 1860 o uso do francês se torna cada vez mais reduzido. Entre a população negra, o uso do patois crioulo ainda é encontrado até finais do século XIX, entretanto no início do século XX já se encontram os primeiros calypsos escritos e cantados em inglês. (PEARSE, 1956).
} 
Uma pessoa de ascendência europeia, normalmente francesa, mas também espanhola, irlandesa, inglesa, italiana e mesmo alemã, que nasceu na ilha e que se considera e é considerado pelos outros um membro do grupo crioulo. Ele pode possivelmente ter ancestrais de ascendência africana, mas para ser aceito como um membro desse grupo, ele teria que ser reconhecido como de descendência 'branca pura'. (...) O termo 'crioulo inglês' significa uma pessoa nascida em Trinidad com ascendência inglesa, com nenhum reconhecimento de ancestrais não-brancos (Brereton 2002, p.3).

As nuances e complexidades das relações cotidianas desses múltiplos sujeitos negros terão lugar também nos carnavais. Portanto, haviam diferentes possibilidades e sentidos das múltiplas identidades raciais em Port-of-Spain.

\section{Cannes Brulées, Canboulay, performance negra}

O Canboulay, por todo período pós-abolição no século XIX, era uma das mais representativas práticas da população negra urbana de Port-of-Spain. O termo é uma expressão crioula a partir da expressão francesa Cannes Brulées [Cana queimada]. Quando algum incêndio começava em uma fazenda, grupos de escravos, chamados de négres jardin [escravos do eito], de diferentes propriedades eram convocados para colher a cana-de-açúcar antes que fosse consumida pelo fogo e controlar o incêndio. Liderados por feitores [slavedrivers] com chicotes, o trabalho desses grupos era iluminado por tochas e marcado pelo ritmo de tambores e por cantos de trabalho. O Cannes Brulées também estaria associado ao uso do fogo para controlar infestações de roedores e usado como método para facilitar a colheita da cana - prática bastante comum nas plantações de cana de açúcar no Brasil. ${ }^{9}$

Até a década de 1830, a plantocracia branca francófona da ilha encenava nos carnavais da cidade uma paródia das práticas dos escravizados. Pintados de tinta preta, zombavam dos valores e padrões estéticos e também do fenótipo. Essa performance racista era chamada de Cannes Brulées.

Segundo carta enviada ao Trinidad Chronicle, em 1881, o Canboulay havia sido encenado ainda nos tempos da escravidão "por muitos membros das classes médias e em muitos casos das classes mais altas"; as mulheres se vestiam de "mulatas" e os homens de "négre jardin"; visitavam as casas mais importantes da cidade com o objetivo de se divertir e divertir os demais, "de um modo inofensivo", e que tudo era feito para "gerar risadas". "Era uma burlesca engraçada, e os performers eram pessoas respeitáveis." ("The Origin of the Canboulay and the old way of playing it", Trinidad Chronicle, 16/03/1881, p. 3. Ver também “The Origin of Canne Boulee”, Port-of-Spain Gazette, 26/03/1881. P1). Essa leitura

\footnotetext{
${ }^{9}$ Para maiores informações sobre o Canboulay ver Cowley, 2003 e Brasil, 2016b. 
nostálgica do Cannes Brulées, foi bastante comum na década de1880, quando o Canboulay já havia se consolidado como uma das principais formas de brincar o carnaval entre a população negra da cidade.

O Canboulay dos negros de Port-of-Spain, entretanto, se constituiu a partir de inúmeras tradições negras da ilha, não apenas a partir da paródia da elite branca - como parte da historiografia defende (Elder, 1998; Crowley, 1956). É possível propor que a formação do Canboulay negro entre as décadas de 1830 e 1850 foi produto da fusão de inúmeras tradições, refletindo as transformações sociais da ilha após a Abolição. Já em 1838, ano da abolição definitiva da escravidão em Trinidad, após o fim do período do Aprendizado, jornalistas compreendiam, ainda que de forma limitada, o carnaval através de um conjunto de práticas associadas à África e seus descendentes. Nas palavras de um autor sob o pseudônimo Authority, encontramos a seguinte descrição no Port-of-Spain Gazette sobre o carnaval de 1838 - ainda antes da abolição definitiva ser aprovada em 01 de agosto daquele ano:

Nós não vamos nos debruçar sobre todas as cenas nojentas e indecentes encenadas em nossas ruas - nós não vamos dizer quantos de nós vimos num estado tão próximo da nudez, [capaz de] enraivecer a decência e chocar a modéstia - nós não vamos descrever particularmente a prática africana de carregar a figura de uma mulher num andor, o qual foi seguido por centenas de negros gritando um música selvagem da Guiné, (lamentamos dizer que nove décimos dessas pessoas eram crioulas) - nós não vamos descrever a luta feroz entre 'Damas' e 'Waterloos' que resultou desses préstitos - mas nós vamos dizer que de uma vez a prática de manter o carnaval, permitindo às classes baixas da sociedade correrem pelas ruas da cidade em fantasias miseráveis, pertence a outros tempos e deve ser abolida.

Centenas de negros gritando uma música selvagem de Guiné; carregando uma alegoria de mulher num pálio, num "costume africano"; com poucas roupas, beirando a nudez. Esses grupos seriam formados por "nove décimos" de crioulos - negros nascidos na ilha, sem contato direto com a África. O texto conclui pedindo a abolição do carnaval e associando diretamente "classes baixas" com negros. Essa associação de classe e raça estará presente ao longo de todo período estudado. Visto que a sociedade de Trinidad possuía um elevadíssimo número de negros em sua composição e um reduzido número de brancos formando as elites econômicas, é recorrente encontrarmos nas fontes a aproximação entre classe e raça, onde classes baixas correspondem a negros e classes altas a brancos. Grupos de classe média negra, intelectuais, indivíduos que ascenderam socialmente através da educação ou outros meios, serão sempre retratados como as exceções desse modelo.

$\mathrm{Na}$ imagem a seguir, de 1836, podemos ver um casal de negros conversando numa "manhã de domingo na cidade" [Port-of-Spain, provavelmente], numa gravura de Richard 
Bridgens, viajante que passou sete anos nas Índias Ocidentais na década de 1820. As roupas e adereços - aparentemente de inspiração francesa - contrastam com a simplicidade do jovem escravo que carrega uma cadeira e os observa com atenção. Essa distinção entre negros livres, muitos deles com melhores posições sociais e os escravizados marcaria as relações sociais de Trinidad ao longo do século XIX.

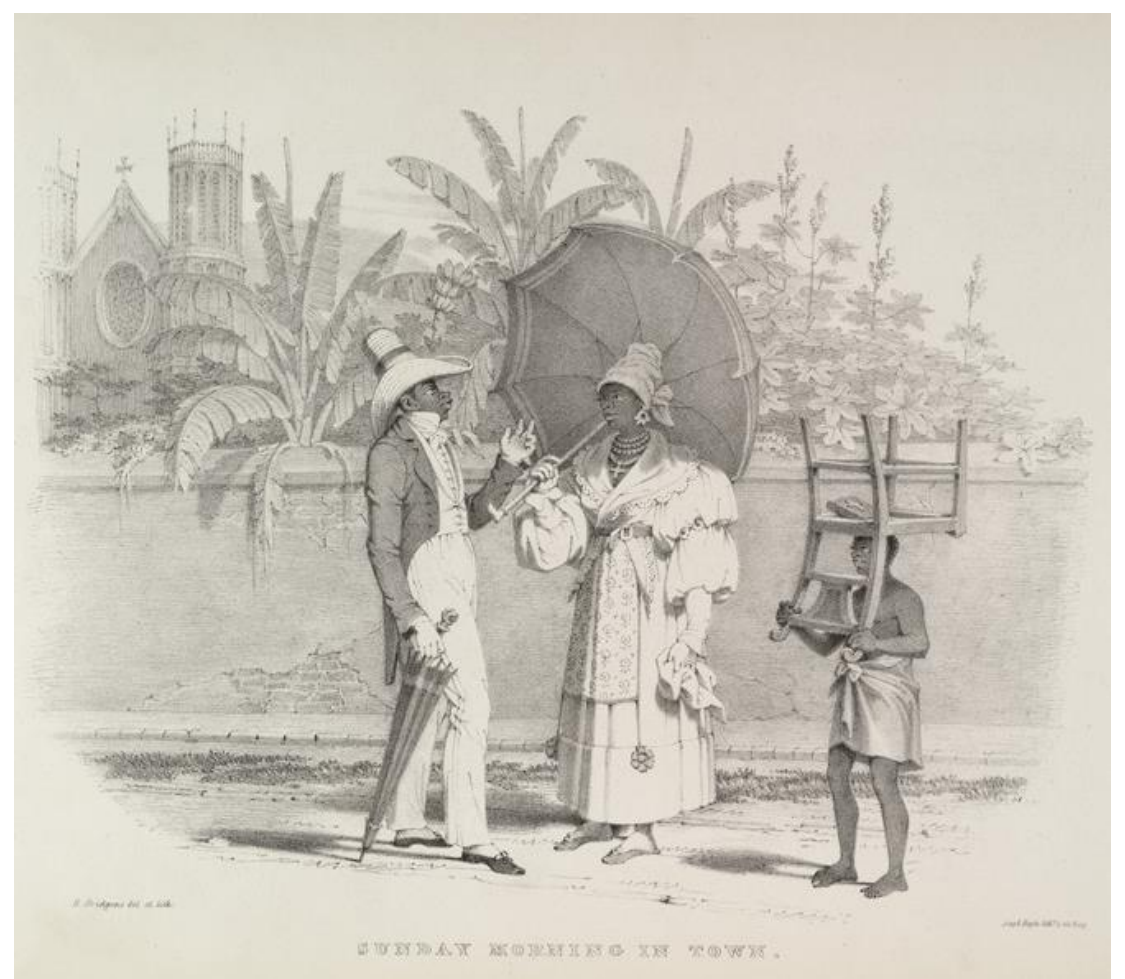

Figura 2. Domingo na cidade. BRIDGENS, Richard., West India scenery with illustrations of Negro character, the process of making sugar, \&c. from sketches taken during a voyage to and residence of seven years in, the island of Trinidad., London: R. Jennings, 1836. Plate 15.

No carnaval também percebemos essa tensão. Ao longo do século XIX, os membros desse grupo de pessoas de cor livre [free coloured people] buscaram se afastar dos estereótipos e práticas dos escravizados; com o fim da escravidão se empenharam em manter distância dos negros livres pobres e seus comportamentos e práticas sociais e culturais. $\mathrm{O}$ carnaval das ruas de Port-of-Spain, representante mais pungente das performances negras de matriz africana, foi rejeitado tanto pelas elites coloniais brancas quanto pela camada da população de ascendência africana, historicamente próxima das tradições francesas. Essa estratégia foi comum em diversas áreas com histórico colonial e escravista. As elites crioulas de Luanda e os membros da imprensa negra paulista, em contextos tão variados, buscaram cada qual a sua maneira se afastar de comportamentos, referências e performances culturais que os aproximassem dos escravizados, seu passado, e das representações correntes sobre África como continente atrasado e primitivo. A incorporação de valores da branquitude europeia foi meta e estratégias para muitos membros desses grupos de negros que Revista de Estudos e Pesquisas sobre as Américas V.12 N.3 2018 ISSN: 1984-1639 
compunham uma classe média urbana em busca de melhores posições na sociedade e como caminho para aliviarem o peso das experiências racistas (Sobre Luanda ver Dias 1984, e sobre São Paulo ver Pires, 2006).

Em Trinidad, tais grupos médios negros só iriam se interessar e participar dos carnavais nas ruas com afinco a partir da virada do século XIX para o XX, num processo de ampliação das bases sociais da festa - um processo histórico que não cabe nos limites desse artigo ( Sobre a participação de setores médios negros no carnaval a partir de 1900 ver Powrie, 1956). Contudo, no período aqui estudado, o carnaval das ruas esteve circunscrito às camadas mais pobres, de trabalhadores urbanos, formados pela população negra, ex-escravizada e seus descendentes diretos na maioria.

Um dos homens negros que, através da educação, conseguiu conquistar posições de destaque na sociedade trinitária, foi Lewis Osborn Inniss. Memorialista importante para o estudo das culturas populares da ilha, especialmente as tradições negras, Inniss nasceu na Guiana em 1848 e chegou em Trinidad em 1852. Foi um dos mais prolixos autores dos anos 1890, produzindo textos sobre gramática crioula, folclore, contos e carnaval (Cudjoe 2003, p. 328). Ele descreveu o Canboulay de antes de 1858 da seguinte forma:

À meia-noite do domingo de carnaval, o sopro de cornetas ou garrafas vazias [...] foi o aviso para a reunião dos grupos, Belmond, Corbeux Town, Dry River, Dernier Point, etc. etc. Liderados pelos seus campeões que manejavam os cacetes [hallé baton] com destreza, com um grande tambor [tambour] e uma coleção de chocalhos para dar a música, tochas feitas de madeira resinosa para dar luz, marcharam pelas ruas gritando canções obscenas. A cidade estava numa escuridão total [...]. Quando eles chegavam a algum local conveniente, o tocador de tambor colocava seu instrumento no chão e sentando-se nele começava a tocar o tambor, as mulheres que carregavam os chocalhos faziam vigorosos acompanhamentos enquanto a multidão dançava Corlindas, as mulheres cantavam Bel-airs e os homens lutavam com cacetes [hallé baton] (Inniss, 1932, pp. 12-13).

Segundo ele, o Canboulay era praticado por grupos fundados a partir de determinadas regiões da cidade - Belmont, Dry River - e seus préstitos eram anunciados pelo toque de cornetas. Tambores e chocalhos [shaq-shaqs] faziam o acompanhamento musical, tochas eram carregadas, iluminando as ruas. As mulheres cantavam o coro enquanto os homens dançavam e lutavam usando os sticks [cacetes]. Nessa performance também era comum a presença de negros acorrentados, outras bradando chicotes, em clara alegoria dos tempos do cativeiro.

Em 1847, um viajante inglês de nome Charles Wiliam Day observou o carnaval na cidade de Port-of-Spain. Sua descrição aponta para uma festa muito plural, tanto nas formas 
quanto nos seus sujeitos sociais. Em seu texto, marcado do olhar preconceituoso e "civilizador" dos protestantes europeus, a rua é o palco tanto para membros da elite branca quanto para descendentes de indígenas das colônias espanholas se divertirem. Porém, também reflete como esse palco estava sendo conquistado e reinventado pela população negra da cidade.

Os mascarados desfilavam nas ruas em grupos de dez a vinte, ocasionalmente juntando forças em procissão. Os primitivos eram negros, quase tão nus quanto se deve, borrados com verniz preto. Um dos membros dos grupos tinha uma longa corrente e cadeado preso à sua perna, a qual os outros puxavam. O que isso tipificava, eu era incapaz de apreender; porém, como o acorrentado era ocasionalmente jogado ao chão, e tratado com uma bastonada simulada, provavelmente representava a escravidão. Cada mascarado estava armado com um robusto cajado, de modo que superavam o número de policiais na proporção de dois para um, se a ocasião se apresentasse. Grupos de mulheres negras dançavam pelas ruas, cada clique distinto por corpetes da mesma cor. Todos os negros, homens e mulheres, vestiam uma máscara branca cor de carne, seus cabelos de lã [woolly hair] cuidadosamente oculto por lenços; isso, contrastando com os seios e braços negros, era engraçado ao extremo. Aquelas senhoras que miram na civilização superior, vestidas de sapatos e meias, invariavelmente vestiam suas extremidades pedais em meias de seda rosa e sapatos infantis azuis, brancos e amarelos [...] Para os homens, o personagem predominante era o Polichinelo; [Assim como] Piratas, corsários turcos, Highlanders, índios da América do Sul, mortes. [...] Reparei que onde quer que uma máscara negra aparecesse, era certo ser um homem branco (Day 1852, p. 313-15).

Nessa descrição ainda estão presentes foliões brancos com rosto pintado de preto, uma grande multiplicidade de fantasias e práticas. Mas também aponta para representações da escravidão e a paródia da vida da elite branca em performances de homens e mulheres negras, menos de uma década após a abolição definitiva da escravidão na colônia. Esse momento inicial Pós-Abolição já mostrava o carnaval como um espaço de confluência de diversas práticas culturais que iriam formar o chamado carnaval Jamette, ${ }^{10}$ que encontraria seu auge nas décadas de 1860 e 1870 na cidade de Port-of-Spain: formação de grupos desfilando pelas ruas, corpos pintados de preto, correntes em volta das cinturas, a presença dos cacetes, das fantasias zombando a "civilização superior", mesclados com personagens dos carnavais europeus, tochas, tambores e desafios verbais.

Os sujeitos criadores dessa performance negra, diretamente associada tanto ao passado escravista e sua memória, quanto à experiência social urbana pós-abolição, eram negros e negras, moradores das Barracks da capital da colônia:

\footnotetext{
${ }^{10}$ Termo que teria origem na palavra francesa diametre. Representava a população "a baixo do diâmetro da respeitabilidade" (Brasil, 2016a, p. especialmente parte 3)
} 
A população mais pobre da cidade, moradora das chamadas Barrack- grandes casarões, com pátio interno, onde os cômodos eram divididos entre várias famílias, numa configuração semelhante aos cortiços do Rio de Janeiro do mesmo período -, entre as décadas de 1840 e 1870, desenvolveu e ampliou os grupos de Canboulay, constituindo-se como uma das principais estratégias de formação de identidades e como uma das centrais características dos carnavais da cidade. Os sujeitos responsáveis pela criação e manutenção desses grupos eram homens e mulheres negros trabalhadores urbanos, jovens, vivendo em dificílimas condições de vida, disputando empregos, água, amores, prestígio com os demais grupos de outras Barrack Yards (Brasil, 2016b, p.53).

Portanto, o Canboulay dos carnavais Pós-Abolição apresentava uma série de práticas e tradições negras que remontavam a memórias da África e do cativeiro, mais do que apenas uma atualização da sátira realizada pelas elites francófonas anteriormente. Como afirmou Cowley,

Acompanhado pelo som de tambores e pelo canto e lamento dos participantes, esse acentuado lembrete da escravidão era quase certamente muito próximo da realidade do passado para o conforto de uma culpada (e temerosa) plantocracia. Aqueles que haviam previamente parodiado o Canboulay quando o carnaval era sua prerrogativa (Cowley 1992, p. 220).

Mas também estava diretamente associada às batalhas, disputas e alianças construídas no cotidiano urbano. Por conseguinte, ocupar as ruas da capital nos dias de Carnaval representava uma oportunidade de representação pública de críticas ao passado escravista e às práticas racistas encampadas pelas elites coloniais no presente.

Portanto, após esse percurso entre os anos iniciais da ocupação britânica da ilha até as primeiras décadas do Pós-Abolição, podemos chegar a algumas conclusões. Primeiro, já havia mobilizações negras antes do ato abolindo a escravidão em 1834. Mesmo que essa mobilização fosse muito mais recente do que em outras regiões do Atlântico, pois o tráfico de escravos irá se intensificar apenas entre 1797 e 1805, percebemos que a população negra escrava, liberta e livre - criou formas de se organizar e estar presente no período festivo que se iniciava com o Natal e se estendia até o Carnaval. Segundo, o carnaval, mesmo com predominância das elites francófonas, teve participação negra nos anos 1830, gerando a reação das autoridades coloniais, que buscaram estabelecer formas de controle. Terceiro, a abolição da escravidão foi um marco importante também para a história do carnaval, visto que se intensifica a participação negra na festa, catalisa práticas festivas que lembravam do tempo do cativeiro, das lutas pela liberdade e de memórias da África.

A realização de uma história social da cultura nos mostrou que tais elementos identitários estiveram presentes nas disputas por emprego, moradia, melhores condições de vida e nas batalhas constantes por direitos e por espaços de autonomia para homens e mulheres negras da ilha de Trinidad e de todo o Caribe que para lá migraram. As 
performances que são criadas nos carnavais do Pós-abolição dialogam com nexos culturais e sociais muito profundos, calcados no processo de abolição da escravidão e nas experiências negras no Pós-Abolição.

\section{Referências Bibliográficas}

BECKLES, H. Natural Rebels: A Social History of Enslaved Black Women in Barbados, Rutgers University Press, 1989a.

BECKLES, H. and SHEPHERD, V. Saving Souls: The Struggle to End the Transatlantic Trade in Africans, Ian Randle Publishers, 2007b.

BORDE, P.-G.-L. Histoire de l'île de la Trinidad sous le gouvernement espagnol, Paris, Maisonneuve, 1876.

BRASIL, Eric. 'Carnavais Atlânticos: Cidadania e Cultura Negra no pós-abolição do Rio de Janeiro, Brasil e Porto de Espanha, Trinidad (1838-1920). Tese de doutorado. Programa de Pós-Graduação em História Social, Universidade Federal Fluminense, 2016a.

BRASIL, Eric. 'Carnaval como direito: A Revolta Canboulay de 1881, em Porto de Espanha, Trinidad.' Revista Eletrônica da ANPHLAC, 0/0, pp.48-77, $2016 \mathrm{~b}$.

BRASIL, Eric. 'Cucumbis Carnavalescos: Áfricas, carnaval e abolição (Rio de Janeiro, década de 1880)'. Afro-Ásia, /49, pp.273-312, 2014.

BRERETON, B. A History of Modern Trinidad: 1783-1962, Portsmouth, Heinemann, 1981.

BRERETON, B. Race Relations in Colonial Trinidad 1870-1900, Cambridge, Cambridge University Press, 2002.

BRIDGENS, R. West India scenery with illustrations of Negro character, the process of making sugar, \&c. from sketches taken during a voyage to and residence of seven years in, the island of Trinidad., London, R. Jennings, 1836.

CLARKE, C. 'Demographic Change and Population Movement' in K. O. Laurence (ed.), General History of the Caribbean, Vol IV: The long Nineteenth Century: Nineteenth Century Transformations. Paris; Londres, UNESCO; Macmillian Educational, pp. 259-282, 2011.

COWLEY, J. 'Music \& migration: aspects of black music in the British Caribbean, the United States, and Britain, before the independence of Jamaica and Trinidad \& Tobago' Tese de Doutorado, 1992. 
COWLEY, J. Carnival, Canboulay and Calypso: Traditions in the Making, Cambridge, Cambridge University Press, 2003.

CROWLEY, D. J. 'The Traditional Masques of Carnival'. Caribbean Quarterly, 4/3, pp.194223, 1956.

CUDJOE, S. R. Beyond Boundaries: The Intellectual Tradition of Trinidad and Tobago in the Nineteenth Century, Wellesley, Massachusetts, University of Massachusetts Press, 2003.

DAY, C. W. Five Years' Residence in the West Indies - Vol I, Londres, Colburn and co, 1852.

DIAS, J. 'Uma questao de identidade: respostas intelectuais as transformaçoes economicas no seio da elite Crioula da Angola Portuguesa entre 1870 e 1930'. Revista internacional de estudos Africanos, /1, pp.61-94, 1984.

DRESCHER, S. Abolition: A History of Slavery and Antislavery, Cambridge University Press, 2009.

DRESCHER, S. Abolição: Uma história da escravidão e do antiescravismo, São Paulo, Editora UNESP, 2011.

ELDER, J. D. 'Cannes Brûlées'. TDR (1988-), 42/3, pp.38-43 CR-Copyright \&\#169; 1998 The MIT Press, 1998.

FERGUS, C. "'Dread of Insurrection”: Abolitionism, Security, and Labor in Britain's West Indian Colonies, 1760-1823'. The William and Mary Quarterly, 66/4, pp.757-780, 2009.

FERGUS, C. Revolutionary Emancipation: Slavery and Abolitionism in the British West Indies, Lousiana, Baton Rouge: Louisiana State University Press, 2013.

FONER, E. Nada além da liberdade: a emancipação e seu legado, Rio de Janeiro, Paz e Terra, 1988.

FRASER, L. M. History of Trinidad., Port-of-Spain, G.P.O, 1896.

HANDBOOK OF TRINIDAD AND TOBAGO., Port-of-Spain, Government of Trinidad and Tobago, 1924.

HOLT, T. C. The Problem of Freedom: Race, Labor, and Politics in Jamaica and Britain, 1832-1938, JHU Press, 1992.

INNISS, Lewis O. Carnival in the Old Days (From 1858), Beacon, Vol.1, No.12, April 1932, pp. $12-13$

LIVERPOOL, H. C. Rituals of Power and Rebellion: The Carnival Tradition in Trinidad and Tobago, 1763-1962, Chicago, Research Associates School Times, 2001.

LÓPEZ. Rafael Brea. Santiago de Cuba: Carnaval y guerras de independencia (Siglo XIX). Batey. Revista Cubana de Antropología Sociocultural. Vol. III, No 3, 2013. pp. 98-113 
LOVELACE, E. 'The Emancipation-Jouvay Tradition and the Almost Loss of Pan'. TDR (1988-), 42/3, pp.54-60, 1998.

MATTHEWS, G. 'Trinidad: A Model Colony for British Slave Trade Abolition'. Parliamentary History, 26/4S, pp.84-96, 2007.

MATTHEWS, G. Caribbean Slave Revolts and the British Abolitionist Movement, Louisiana State University Press, 2006.

MEITCHELL, R. 'Significando: carnaval afro-creole em New Orleans do século XIX e início do XX' in M. C. P. Cunha (ed.), Carnavais e outras F(R)estas. Ensaios de história social da cultura. Campinas, SP, Editora da Unicamp, pp. 41-70, 2002.

MOORE, R. D. Nationalizing Blackness: Afrocubanismo and Artistic Revolution in Havana, 1920-1940, Pittsburgh, Pa, University of Pittsburgh Press, 1997.

NEPOMUCENO, N. (Bebel) 'Festas negras do ciclo natalino no século XIX na América do Sul e no Caribe'. Revista Latino-Americana de Estudos Avançados, 1/1, pp.101-117, 2016.

PEARSE, A. 'Carnival in Nineteenth Century Trinidad'. Caribbean Quarterly, 4/3, pp.175193, 1956a.

PEARSE, A. 'Education in the British Caribbean: social and economic background'. Vox Guyanae, 2/1, pp.9-24, 1956 b.

PIRES, A. L. C. S. Imprensa negra paulista e as associações dos homens de cor: política e cultura no Brasil republicano (1915-1945), Belo Horizonte, Fundação Universidade Federal do Tocantins, 2006.

POWRIE, B. E. 'The Changing Attitude of the Coloured Middle Class Towards Carnival'. Caribbean Quarterly, 4/3/4, pp.224-232, 1956.

SAMAROO, B. 'The imigrant Communities' in K. O. Laurence (ed.), General History of the Caribbean, Vol IV: The long Nineteenth Century: Nineteenth Century Transformations. Paris; Londres, UNESCO; Macmillian Educational, pp. 223-258, 2011.

SAN MIGUEL, P. 'Economic activities other than sugar' in K. O. Laurence (ed.), General History of the Caribbean, Vol IV: The long Nineteenth Century: Nineteenth Century Transformations. Paris; Londres, UNESCO; Macmillian Educational, pp. 104-133, 2011.

WILLIAMS, E. History of the people of Trinidad \& Tobago, New York, Praeger, 1964.

WOODING, H. O. B. 'The Constitutional History of Trinidad and Tobago'. Caribbean Quarterly, 6/2/3, pp.143-159, 1960

YELVINGTON, K. A., Sainton, J.-P., Hector, M., and Casimir, J. 'Caribbean Social Structure in the Nineteenth Century' in K. O. Laurence (ed.), General History of the Caribbean, Vol IV: 


\title{
The long Nineteenth Century: Nineteenth Century Transformations. Paris; Londres,
} UNESCO; Macmillian Educational, pp. 283-333, 2011.

\author{
Abolição e carnaval: performance e experiência social negra em Trinidad (cc. 1790- \\ 1850)
}

Resumo: Esse artigo pretende analisar as relações entre o processo de abolição da escravidão em Trinidad e as formas de mobilização social e performances carnavalescas de homens e mulheres negras entre o início da ocupação britânica da ilha até as primeiras décadas pós-abolição (cc. 1790-1850). Para tanto, o texto está dividido em três tópicos: no primeiro, iremos analisamos as formas de participação de homens e mulheres negras durante a vigência do regime escravista na ilha, assim como as tentativas coloniais de repressão e controle e os argumentos da imprensa local na construção do mito do carnaval branco, ordeiro e civilizado (sic); em seguida, buscamos investigar os impactos demográficos, nas relações de trabalho e nas tensões sociais após 1834; por fim, focamos a análise na formação do Canboulay negro entre as décadas de 1830 e 1850 , propondo uma reflexão sobre seus sentidos políticos num contexto de liberdade. A pesquisa utilizou um conjunto amplo de fontes primárias arquivadas na British Library e no National Archives em Londres, Inglaterra; obras de memorialistas, folcloristas e a produção historiográfica.

Palavras-chave: Carnaval, Abolição da Escravidão, Caribe, Trinidad, Performance negra

\section{Abolition and Carnival: Black performance and social experience in Trinidad (cc. 1790- 1850)}

Abstract: This article aims to analyze the relationship between the process of abolishing slavery in Trinidad and the forms of social mobilization and carnival performances of black men and women between the beginning of the British occupation of the island and the first decades after the abolition (c.1790-1850). Therefore, the text is divided into three topics: in the first one, we will analyze the forms of participation of black men and women during the last decades of slavery on the island, as well as the colonial attempts of repression and control and the arguments of the local press in the construction of the myth of a white, orderly and civilized carnival ( sic); then we seek to investigate demographic impacts, work relationships, and social tensions after 1834; finally, we focused the analysis on the formation of black Canboulay between the 1830s and 1850s, proposing a reflection on his political meanings in a context of freedom. The research used a wide array of primary sources filed at the British Library and the National Archives in London, England, and works of memorialists, folklorists, and historiographical production.

Key-words: Carnival, Abolition of Slavery, Caribbean, Trinidad, Black Performance

\begin{abstract}
Abolición y carnaval: performance y experiencia social negra en Trinidad (cc 1790-1850)
Resumen: Este artículo pretende analizar las relaciones entre el proceso de abolición de la esclavitud en Trinidad y las formas de movilización social y performances carnavalescas de hombres y mujeres negras entre el inicio de la ocupación británica de la isla hasta las primeras décadas post-abolición (cc. 1790-1850). Para ello, el texto está dividido en tres tópicos: en el primero, examinaremos las formas de participación de hombres y mujeres negras durante la vigencia del régimen esclavista en la isla, así como los intentos coloniales de represión y control y los argumentos de la prensa local en la construcción del mito del carnaval blanco, ordenado y civilizado (sic); A continuación, buscamos investigar los impactos demográficos, las relaciones de trabajo y las tensiones sociales después de 1834; por fin, enfocamos el análisis en la formación del Canboulay negro entre las décadas de 1830 y 1850, proponiendo una reflexión sobre sus sentidos políticos en un contexto de libertad. La investigación utilizó un conjunto amplio de fuentes primarias archivadas en la British Library y en el National Archives en Londres, Inglaterra; obras de memorialistas, folcloristas y la producción historiográfica.
\end{abstract}

Palavras-chave: Carnaval, Abolición de la Esclavitud, Caribe, Trinidad, Performance Negra 